\title{
Hacia una teología de la identidad judía en Arthur Allen Cohen
}

\author{
Towards a theology of Jewish identity in Arthur Allen Cohen
}

\author{
Autor: Miguel Giménez Blunden (PhD) \\ mgblunden@hotmail.com \\ Universidad Rovira i Virgili (Tarragona) (2019)
}

\section{Resumen}

En este artículo intentaré dilucidar el sentido de la identidad judía en la obra de Arthur Allen Cohen tal y como la entiende él, a partir de sus propias afirmaciones en dos textos fundacionales, ¿Por qué escojo ser judío?, escrito en 1959 y en su libro seminal El judío natural y sobrenatural (1962), que lo da a conocer como teólogo, una de las obras clave del judaísmo norteamericano contemporáneo. El análisis es de los aspectos esenciales tanto del artículo como del libro y no es sino un "pretexto" para entender de dónde parte y hacia donde se dirigen los principios fundacionales del discurso teológico de Cohen y cómo configuran un concepto de identidad, basado en una visión idiosincrática del discurso religioso judío. Esto estructura el texto partiendo de dos presupuestos que vertebran el artículo. Contextualizaremos lo que se entiende por "teología" en el mundo cultural norteamericano, nos adentraremos en su biografía y obra, analizaremos su "elección" del judaísmo como fundamento de su vida y centraremos nuestra atención en dos aspectos relevantes de una obra inmensamente culta y densa, un punto focal en una relativamente poco conocida obra del pensamiento judío contemporáneo.

Palabras clave: Teología, identidad, judío natural/sobrenatural.

\begin{abstract}
In this article I will try to illuminate the sense of Jewish identity in the work of Arthur Allen Cohen as he understands it, from his own statements in two foundational texts, Why I Choose to be a Jew (1959) and his seminal book The Natural and the Supernatural Jew (1962), which makes him known as a theologian and one of the key works of Contemporary American Judaism. The analysis of the essential aspects of both the article and the book is only our "pretext", the beginning and the finality of the foundational principles of Cohen's theological discourse and also how they shape a concept of identity, based on an idiosyncratic vision of Jewish religious discourse. The text is structured on two presuppositions that support the article. I will contextualize what is understood by "theology" in the North American cultural world. I will consider his biography and works, analyze his "choice" of Judaism as the foundation of his life and attention will be focused on two relevant aspects of an immensely cultured and dense work, a focal point in a yet fairly unknown work of Contemporary Jewish Thought.
\end{abstract}

Key words: Theology, identity, Natural/Supernatural Jew. 


\section{Introducción y punto de partida. Orientación de nuestra lectura ${ }^{1}$}

Arthur Allen Cohen (1928-1986) es una de las figuras más relevantes del pensamiento judío contemporáneo en el ámbito norteamericano de la segunda mitad del siglo XX. Es americano y eso ya marca una diferencia substancial. Es una de muchas figuras ineludibles para comprender la evolución del pensamiento judío contemporáneo posterior a la Segunda Guerra Mundial. Su perspectiva no viene condicionada como la de muchos de sus congéneres europeos por la huída en la Diáspora forzada por las inclemencias históricas de Alemania y otros países europeos, incardinados después en las mejores universidades británicas, canadienses, norteamericanas e israelíes, sino que es la visión de un judío de segunda generación, asimilado y plenamente integrado en la cultura de los Estados Unidos ${ }^{2}$. Cohen desarrolla sus reflexiones de forma independiente y nueva, adaptada a una cosmovisión sin prejuicios históricos y que sin embargo, en una vertiente doble, no ha olvidado las grandes figuras de antaño de la Edad Moderna, Ilustración y los siglos XIX y XX, además del llamado "judaísmo germánico" (Solomon Ibn Verga, Moses Mendelssohn, Leopold Zunz, Samsom Raphael Hirsch, Chaim Nachman Bialik, Hermann Cohen, Leo Baeck, Franz Rosenzweig, Martin Buber), sino que además incorpora lo que vino a llamar "el momento americano", con autores tan significativos como Mordecai Kaplan ${ }^{3}$, Milton Steinberg ${ }^{4}$, Abraham Joshua Heschel $^{5}$ y Will Herberg ${ }^{6}$.

${ }^{1}$ Este artículo forma parte de investigaciones iniciadas por el autor en 2012, de la que han sido fruto dos artículos (2012 y 2015), una parte de una una primera tesis doctoral inédita sobre Emil Fackenheim defendida en 2016 (p. 311-328) y la esencial parte en una segunda tesis doctoral sobre Cohen y su concepto de identidad iniciada este mismo año (2019) en la Universidad Rovira i Virgili, en Tarragona (España) bajo la dirección del profesor Angel Belzunegui Eraso.

2 Para una excelente introducción a las complejas relaciones en la sociedad norteamericana entre las comunidades judías sefarditas hispano-portuguesa, la judeo-germana y la procedente de los shtetl de la Europa oriental, nada mejor que la introducción que haría sobre su maestro Milton Steinberg en: Cf. Cohen, Arthur A. (Edición e introducción). The Anatomy of Faith: Theological Essays of Milton Steinberg (1960), pág. 11-60.

${ }^{3}$ KAPLAN, Mordecai (1881-1983), uno de los fundadores de la corriente de judaísmo conocida como reconstruccionismo, en la que se reformulara la noción de judaísmo a raíz de los cambios del mundo moderno, alejándose de un exclusivismo transcendente hacia una visión más acorde a la realidad histórica, social y científica del mundo.

${ }^{4}$ STEINBERG, Milton (1903-1950), uno de los grandes teólogos judíos de la primera mitad del siglo XX, maestro del propio Cohen y uno de los mayores críticos de Kaplan.

${ }^{5}$ HESCHEL, Abraham Joshua (1907-1972), rabino y teólogo, una de las mentes más preeminentes del Jewish Theological Seminary de Nueva York.

${ }^{6}$ Herberg, Will (1901-1977), pensador judío conservador norteamericano, que recalcó entre muchas otras cosas, el fundamento judeo-cristiano que debían tener las sociedades modernas europea y norteamericana. 
Nuestro artículo aborda algunas de las intuiciones teológicas primigenias de Cohen que configuran su pensamiento ulterior y más concretamente, lo que entiende por "identidad judía". Para ello nos basamos fundamentalmente en dos textos: el artículo Why I choose to be a Jew ("Por qué quiero ser judío") de 1959 y algunos puntos de The Natural and the Supernatural Jew (El judío natural y sobrenatural), que se publica por primera vez en 1962 y contiene buena parte de sus reflexiones teológicas primeras, que luego tienen continuidad a lo largo de su obra. Es, sin duda, junto con The Tremendum (1981), libro dedicado a la comprensión del Holocausto, su obra de mayor calado y que le dio primero a conocer.

Arthur Allen Cohen fue teólogo, filósofo, editor y novelista, siendo cada una de estas facetas, expresión de la complejidad de su ser y su pensamiento. Sus afirmaciones y su particular visión del judío en el mundo moderno, engloba su idiosincrasia y su percepción particular y original, del lugar que ocupa el judío y particularmente, él mismo como "judío vocacional” en los también convulsos tiempos de la segunda mitad del siglo XX. Su misma biografía fue la un hombre poco proclive a ser encasillado, a sentirse limitado o constreñido por las autoridades académicas, e incluso por los límites que le imponía el judaísmo, que como gustaba decir, fue para él (inmerso en una cultura fundamentalmente cristiana), fruto de una conversión, un destino elegido libremente, nunca impuesto y nunca inevitable ${ }^{7}$.

Nuestro breve artículo pretende analizar el concepto de identidad judía en esta obra a partir de sus afirmaciones teológicas. Identidad judía y teología creemos van indefectiblemente unidas en su pensamiento. Cabe decir que desde el punto de vista de la cronología de la redacción de su obra, entendemos y afirmamos que su noción de identidad se puede entender a tres niveles distintos ${ }^{8}$ :

a) Autopercepción del discurso teológico en la tensión judío natural/judío sobrenatural;

b) Identidad judía como tensión entre el judaísmo y el cristianismo (que no es objeto de este estudio) y,

c) Cómo entender el discurso de Cohen en el contexto del pensamiento judío contemporáneo después de la Shoá ${ }^{9}$. Solamente el primer sentido es el que valoraremos aquí.

La centralidad de nuestro análisis es de orden teológico. Desde un punto de vista metodológico, creemos esencial recalcar este aspecto precisamente porque resulta central en esta obra, la relación del concepto de identidad judía con su "teología". Pero ello plantea la necesidad de partir de dos presupuestos conceptuales:

\footnotetext{
${ }^{7}$ Stern, D. \& Mendes-Flohr, P. (1998), 22.

${ }^{8}$ Dicho sentido se deriva del desarrollo temático-cronológico de su obra y es nuestra posición esencial en este artículo y de la tesis doctoral hemos mencionado anteriormente.

${ }^{9}$ Tema que hemos abordado en un artículo anterior publicado en España citado en la bibliografía GIMÉNEZ BLUNDEN, Miguel (2012). Arthur Allen Cohen y el Tremendum. Una aproximación teológica a la Shoah. Revista El Olivo, 75, 87-106.
} 
a) Primero, ¿en qué sentido puede hablarse de una teología y si cabe, de una teología judía en Cohen? Más aun, ¿en qué medida el pensamiento judío norteamericano en la segunda mitad del siglo XX puede considerarse como "teológico" o incluso religioso?

b) ¿Qué sentido tiene el concepto de identidad en Cohen en esta obra partiendo de sus principios teológicos?

Ello supone que este artículo se vertebrará de la siguiente forma y siguiendo los presupuestos siguientes:

- Delimitar el concepto de "teología" en el contexto del judaísmo norteamericano contemporáneo de la segunda mitad del siglo XX;

- Presentación bio-bibliográfica del autor para contextualizar la obra y el sentido de la misma como obra "primigenia", donde por así decirlo, pone los "fundamentos" de su discurso teológico posterior;

- Ver cómo su escrito de 1959 "Porque escojo ser judío" es el punto de partida de sus reflexiones;

- Analizar cinco puntos axiomáticos de la obra de 1962 que puedan orientarnos o acercarnos a una definición de su "identidad" judía y,

- Unas conclusiones que se derivan de lo anterior, los indicios de una hermenéutica inicial de dicha obra, puesto que no es nuestra intención, levantar la bandera de la exhaustividad académica en este artículo.

\section{El contexto cultural judío americano en la "teología": Conceptos previos. Identidad judía y teología en Cohen}

Para mejor entender a Cohen, resulta imprescindible entender en qué contexto cultural intelectual se mueve y qué relación puede establecerse con ellos, a modo de prolegómenos de su pensamiento. Si queremos ahondar en ello, deberemos analizar que entendemos por "teología". Para ello hemos recurrido al profesor Arnold Eisen. Arnold Eisen, profesor en las universidades de Tel Aviv, Columbia, Stanford y finalmente los últimos trece años (2006-2019) rector del prestigioso Jewish Theological Seminary en Nueva York comenta en su artículo "Jewish Theology in North America: Notes on Two Decades"10 , los más recientes cambios en el panorama "teológico" del judaísmo en el panorama americano de las décadas de 1970 a 1990 (y por ende, de cómo se concibe), que sin embargo son aplicables a toda la segunda mitad del siglo XX, donde se sitúa la obra de Cohen, resultando indicativo de la realidad del discurso teológico en el judaísmo de esas décadas y en términos generales, de toda la llamada "teología post-Holocausto".

\footnotetext{
${ }^{10}$ Eisen, Arnold (1991). Jewish Theology in North America: Notes on Two Decades. The American Jewish Year Book, 91, 3-33.
} 
El término "teología” se refiere a “(...) un pensamiento (1) de un carácter sistemático que (2) que está conformado por una competencia filosófica seria y (3) demuestra o prueba una fundamentación real en la historia y la tradición judías" ". Los escritos de las décadas de los 70 y los 80 del siglo pasado se caracterizan por su carácter homilético y divulgativo (en este caso, entendiéndose para un público mayoritario). Sin embargo, la "teología” es por definición, “(...) una actividad elitista dirigida a una audiencia limitada, y su impacto en la masa de los creyentes es prácticamente intrascendente" 12 . Este es particularmente el caso en el contexto norteamericano, donde se abandona ese recorrido "exclusivista", elitista para adentrarse en otras formas de discurso, como son el comentario, el código legal e incluso el ensayo. Pero los problemas que tiene la teología "judía" no son solamente del judaísmo, sino que podrían aplicarse al cristianismo católico y protestante. Estos se agrupan en seis causas esenciales:

a) El particularismo del discurso teológico judío en el contexto americano, entendiendo que el proceso de asimilación cultural supone o presupone o precisa de la "negación" de la identidad judía como fenómeno religioso;

b) La falta de formación de los propios teólogos por motivos diversos (desconocimiento de los fundamentos de pensamiento y tradición bíblicas y de la filosofía moderna europea Kant, Hegel y Heidegger-, a diferencia de autores como el propio Cohen y Emil Fackenheim, los esfuerzos que plantea como contrapartida, el propio pensamiento cristiano para solventar los problemas de la sociedad actual y finalmente, una ignorancia de la teoría social y de la literatura como elementos configurantes en la cultura del siglo XX).

c) Otra diferencia es el enfoque que dan cristianos y judíos al mismo concepto de Dios, siendo que los cristianos indagan en su naturaleza, cuando desde la perspectiva judía, el énfasis se pone en la conducta colectiva en la Presencia de Dios debido a su realidad como Pueblo de la Alianza.

d) La falta potencial de lectores, que se debe en buena a parte, al público al que va dirigido habitualmente el discurso teológico, que engloba cuatro grandes grupos: la propia comunidad teológica, los colegas de la propia universidad (cuyas propias creencias religiosas están en franco declive), los rabinos de comunidades importantes y los legos cultos que tienen interés en dichas cuestiones. Se tiende a ver la práctica de la teología como un mero divertimento más que una actividad que tiene implicaciones en las creencias y estricta observancia de las comunidades religiosas o como un conjunto de lecturas difíciles de entender y de escasa aplicación práctica para el "judío de a pie”.

e) En quinto lugar, está el factor de la "creencia" personal de cada individuo en cada comunidad, habiendo por lo general, más escépticos e incrédulos que creyentes. El problema de la duda es una cuestión acuciante tanto para el judaísmo como para el cristianismo, pero con matices claramente diferenciados. El cristiano/protestante (en el contexto americano) puede abandonar su iglesia por ejemplo, si su pastor no es de su agrado o la comunidad no responde a sus necesidades o él/ella han dejado de creer o compartir una parte del ideario religioso. El judío, sin embargo, mantiene a pesar de sus

\footnotetext{
${ }^{11}$ Eisen, Arnold (1991), 4.

${ }^{12}$ Eisen, Arnold (1991), 4.
} 
creencias personales (un estudio de 2011 comprobó que más del 50\% de los judíos tienen dudas acerca de la existencia de Dios frente a un 10-15\% de sus congéneres de otras confesiones), un compromiso comunitario-cultural-ético-identitario con su comunidad (a su pesar o no). Incluso el judaísmo ortodoxo acepta que un ateo nacido de madre judía pueda ser considerado plenamente judío.

f) En sexto y último lugar, hay que añadir un concepto reciente pero clave para entender el mundo del judaísmo en la segunda mitad del siglo XX, en el contexto norteamericano y esencialmente anglosajón (sin por ello excluir el Estado de Israel): Auschwitz, el Holocausto, la Shoá o la Catástrofe, concepto teológico (aunque evidentemente fundado en una realidad histórica innegable) que se configura como horizonte de toda la reflexión teológica de la segunda mitad del siglo XX.

Esta contextualización no apunta a una escasez de teólogos porque haberlos los hay, que pueden o no compartir o formar parte de la realidad antes descrita. Otra cosa y este es el caso siempre, es la orientación o el posicionamiento particular de cada cual en dicha disciplina, pero la caracterización anterior plantea, al menos conceptualmente, la problemática de un teólogo en el contexto que estamos estudiando.

La figura de Arthur Allen Cohen, es una "anomalía", una excepción del conjunto de sus semejantes, en buena medida, por su propuesta de "judaísmo por elección" y por el peso que da a la "creencia" en Dios. Es decir, lo que le diferencia a él (y no voy a a hacer una comparativa con docenas de notables figuras que representan una pléyade de posturas diferentes y similares) es que su "background" asimilado, de tercera generación de judíos norteamericanos, ubicado dentro del contexto blanco, anglosajón y protestante, destaca por la reivindicación de la "antigua fe", en términos que pueden calificarse como anteriores a la Modernidad (entiendo por este término, los últimos 300 años de historia común europea y norteamericana), con todo un aparato categorial "sui generis" pero que ve en muchos autores de los últimos 500 años, haber visto peligrar la manifestación de su "judeidad" por la irrupción de la Ilustración, el cientifismo y la secularización. Lo novedoso es que su opción por el judaísmo es por un lado, libre (de ataduras familiares, comunitarias, culturales) y fruto de un proceso intelectual, que pasa por la reflexión intelectual, que antes hemos definido por "teología". Y es esta actitud, la que define su "identidad judía".

Como afirma Emily Kopley, otra estudiosa de la figura de Cohen, “(...) la obra de Cohen parte de una tensión entre creer en el Dios judío y no saber cómo hacerlo" "13 y en palabras de su discípulo, estudioso y editor, el catedrático de Harvard David Stern (a quien mencionamos en la bibliografía), precisamente citando algo dicho en conversación privada y en su necrológica de 1987, "Es imposible pensar acerca de Dios sin pensar en la mente que está pensando sobre Dios"14, siendo posiblemente esta idiosincrasia, la que hizo que sus escritos, “(...) pudieran garantizar la creatividad

\footnotetext{
${ }^{13}$ Morgan, M. \& Weitzman, S. (2015), 396.

${ }^{14}$ Stern D. (1987). Arthur A. Cohen: In Memoriam. ORIM: A Jewish Journal at Yale, Vol. II, nº 2, p. 109.
} 
que sería necesaria para la supervivencia del judaísmo en el futuro"15. Para Cohen, no hay interpretación teológica que no sea un reto "existencial" que englobe todo el ser de un judío, y por ende, de su identidad. Por ello y para entender entonces de dónde viene y adónde va Cohen, debemos aludir brevemente a su intensa biografía, donde lo intelectual y lo vital conviven de forma simbiótica.

\section{Biografía}

Arthur Allen Cohen nace en Nueva York el 25 de junio de 1928. Sus padres, Isidore Meyer y Bess Junger Cohen, eran judíos norteamericanos de segunda generación en un contexto asimilado en el que apenas existía la observancia religiosa. A los 16 años ingresa en la Universidad de Chicago para sumergirse en las humanidades, la literatura occidental, filosofía y estudios religiosos. Es ahí donde precisamente toma conciencia del carácter marcadamente cristiano de la cultura que le rodea, lo que le lleva a una crisis de fe llegando al punto de plantearse la conversión al cristianismo. Esto sucede en 1945 y viendo la enormidad de lo que se les venía encima, sus padres decidieron llevarlo no al psiquiatra sino a un rabino. Milton Steinberg (1903-1950), filósofo, teólogo, escritor y la figura más preeminente de su generación, viró al joven Arthur hacia el judaísmo con cursos especializados y el estudio del hebreo. Años más tarde, este particular "camino de Damasco" (tomando el símil de la vida de Saúl de Tarso) queda reflejado en uno de sus primeros artículos, “¿Por qué escojo ser judío?”, publicado en 1959 ${ }^{16}$. Se gradúa en Chicago (B.A.) en 1946 y entre 1946 y 1949, realiza un Máster (M.A.) con una tesis que lleva por título "El concepto de la paradoja en Kierkegaard y Nietzsche" en el Departamento de Filosofía de la misma facultad. La segunda mitad de 1949 se la pasa a instancias de Milton Steinberg en la Universidad Hebrea de Jerusalén estudiando hebreo y ganándose la amistad de sabios como Martin Buber $^{17}$ (de quien escribiría un libro), Ernst Simon y Hugo Bergmann. Entre 1949 y 1951, amplía estudios en el prestigioso Jewish Theological Seminary de Nueva York, uno de los centros más prestigiosos del judaísmo conservador en Norteamérica. Deja el seminario por encontrarlo aislacionista y poco estimulante. Las secuelas de una tuberculosis infantil le permiten librarse de participar en la guerra de Corea.

Los años que siguen, de 1951 a 1969 son los que dedica a su labor editorial. Funda en 1959 la editorial Noonday Press con su amigo, el escritor Cecil Hemley ${ }^{18}$, donde dieron rienda suelga a su pasión por publicar editando a autores tan europeos como Ortega y Gasset y Karl Jaspers y tan marcadamente yiddish como Sholom Aleichem (autor del musical "El violinista en el tejado") e Isaac Bashevis Singer, Premio Nobel de Literatura de 1978 y autor de obras tan destacadas como La

\footnotetext{
${ }^{15}$ Stern D. (1987). Arthur A. Cohen: In Memoriam, p. 112.

${ }^{16}$ Cohen, A. (1959), Harper's Magazine 218 (1307), 63-66; Stern, D. \& Mendes-Flohr, P. (1998), $32-42$.

${ }^{17}$ Buber, Martin (1878-1965), una de las estrellas del firmamento del pensamiento judío del siglo XX, el elaborador de la relación "Yo-Tú" (fundada en la relación entre el hombre y el mundo), profesor en la Universidad Hebrea de Jerusalén y co-traductor (junto con Franz Rosenzweig) del Antiguo Testamento al alemán.

${ }^{18}$ Hemley, Cecil (1920-1969), poeta y traductor de renombre del yiddish, editor y co-fundador de la Noonday Press, editorial que presentaría en los Estados Unidos, obras y autores tan ilustres como Susan Sontag, Boris Pasternak, Jean Paul Sartre, etc.
} 
Familia Moskat o El Esclavo. En 1954 funda otra editorial, Meridian Books, subsidiaria de la primera, que publicaba obras de vanguardistas como Alvin Lustig (cuya viuda Elaine acabaría siendo su mujer) y obras del modernismo europeo. Entre 1956 y 1960 se vende la participación de la primera editorial y la segunda para convertirse en 1961 en el jefe de la sección de libros religiosos de Holt, Rinehart and Winston y de 1964 a 1969, editor jefe y vicepresidente de la división de libros comerciales. En 1956 tomó quizás la decisión más importante en su vida a nivel emocional, su matrimonio con Elaine Lustig, convirtiéndose en Elaine Lustig-Cohen para el resto de su vida, a quien conoció junto a su marido Alvin Lustig, en su época de Meridian Books. Funda en 1973 con ella, la tienda Ex Libris, especializada en al venta de libros de anticuario relacionados con las vanguardias como el surrealismo y el constructivismo ruso. De aquí también el interés en su obra varios libros sobre la obra de artistas contemporáneos como Sonia Delaunay ${ }^{19}$, Herbert Bayer ${ }^{20}$ y Jakob Steinhardt ${ }^{21}$. De 1975 a 1985, sigue una época de extraordinaria productividad, participando en instituciones sobre cultura hebrea y retomando su estudio de la lengua de los Profetas. Sin embargo, por desgracia, fallece el 31 de octubre de 1986, fruto de nueve meses de lucha con la leucemia, trabajando hasta el final, en la publicación de un conjunto de ensayos de casi mil páginas y 140 artículos escritos tanto por él como por las plumas más ilustres del pensamiento judío contemporáneo como Hyam Maccoby, David Flusser, Shalom Rosenberg, Richard L. Rubenstein, Emil Fackenheim, Gershom Scholem, Moshe Idel, Jacob Neusner y Nahum N. Glatzer $^{22}$.

Una breve presentación de su obra contextualizará su aportación intelectual y permitirá dar una perspectiva de Cohen como pensador, escritor y editor, a la vez que de preocupaciones personales que tienen su fundamento en su "alma" de teólogo. Al referirnos a su obra, nos referimos a los libros publicados, no al material inédito, correspondencia, etc., presente en sus archivos en la Beinicke Library en Yale.

\section{Obra}

Según Julian Levinson, son cinco las facetas que podemos describir de Arthur Allen Cohen: el teólogo judío neo-ortodoxo, el exitoso editor de libros, el heraldo de la revolución de los libros de tapa blanda, el magnánime organizador de salones de eventos y de antologías, el novelista hagádico y el desafiante y en ocasiones críptico teórico post-Holocausto ${ }^{23}$. Hay a pesar de todo, una unidad

\footnotetext{
${ }^{19}$ Delaunay, Sonia (1885-1979), una de las artistas francesas más renombradas de su época, conocida por la abstracción geométrica, concepto artístico que la caracterizó.

20 Bayer, Herbert (1900-1985), diseñador gráfico, escultor y arquitecto, el último representante del movimiento conocido como Bauhaus.

21 Steinhardt, Jacob (1887-1968), artista judío germano, instalado en Israel conocido por sus grabados en madera y litografías.

${ }^{22}$ Cohen, Arthur y Mendes-Flohr, Paul (Ed.) (1987).

${ }^{23}$ Levinson, J. (2003), 259.
} 
esencial a lo largo de todo su pensamiento ${ }^{24}$, ya sea en sus escritos teológicos como en su obra novelística, o como diría él mismo:

"Mantengo la unidad de ambos cuerpos de trabajo (...) no como la suspensión azarosa de partículas en un campo magnético, sino que cual un imán humano, teniendo voluntad e inteligencia, puedo determinar eficientemente lo que exprese y cuanto debo suprimir ${ }^{, 25}$.

Desde el punto de vista de su producción escrita, pueden establecerse tres etapas fundamentales en su vida:

a) De 1944 a 1951, su formación académica e universitaria y el viraje "consciente" hacia una identidad judía "por elección".

b) De 1951 a 1967/9, su etapa como editor como "trabajo diurno" y su labor como teólogo como "trabajo nocturno" $26 \mathrm{y}$,

c) De 1967/9 hasta 1986, su consolidación como novelista, teólogo y divulgador. Los textos que analizaremos se ubican claramente en el segundo periodo de su obra.

A diferencia del mundo de la secularización en el que vivimos inmersos y con notables alusiones a Lo Santo de Rudolf Otto, en su obra sobre Martin Buber (1957), Cohen preconiza la importancia de una dimensión sobrenatural del mundo, al afirmar que: "Martin Buber es el que ve Lo Santo como el centro de la condición humana, cuya visión de lo Santo es esencialmente hebraica, pero cuya preocupación está dirigida hacia el logro de una comunidad en la que lo Santo, más allá de credos y catecismos, pueda ser realizado" 27 , buscando con ello y a través de su doctrina del Yo-Tú, "(...) la búsqueda de lo santo, el intento de iluminar su alcance, su realidad, su eficacia para moldear la búsqueda del hombre de la auténtica comunidad y plenitud" ${ }^{28}$. De este modo, su visión del judaísmo no es sólo "hacia dentro", sino en su relación con los "demás pueblos".

En 1962, a los 34 años publica The natural and the Supernatural Jew como manifiesto de su ideario teológico. A continuación en 1964, movido por la coyuntura histórica, en un momento de disturbios civiles y lucha por los derechos de las comunidades más desfavorecidas de Estados Unidos, Cohen publica un libro sobre el comunismo de Mao Tse-Tung (1893-1976), el indiscutible líder de la revolución china y fundador de la República Popular China en 1949. Se habla del Mao filósofo, de la revolución, de la forma del Estado, de la transición al socialismo, de las contradicciones internas

\footnotetext{
${ }^{24}$ Stern, D. \& Mendes-Flohr, P. (1998), 21.

${ }^{25}$ Stern, D. \& Mendes-Flohr (1998), 257/421.

${ }^{26}$ Stern, D. \& Mendes-Flohr, P. (1998), 15.

${ }^{27}$ Cohen A. (1957), 9-10.

${ }^{28}$ Cohen A. (1957), 10.
} 
de una sociedad socialista y de la transición al comunismo, fundamentada en las llamadas "comunas populares".

En 1971 Cohen aborda la siempre compleja relación entre judaísmo y cristianismo. En El Mito de la tradición judeocristiana y otros ensayos disidentes, una antología de ensayos que se publican entre 1957 y 1971, se asombra ante la reacción especialmente de la comunidad católica y el hecho de que más que un acercamiento entre ambas comunidades, lo que siempre había existido era una equidistancia que no nunca propició una solución real ni una verdadera reconciliación, sino que “(...) mi disputa es que más que una tradición de continuidad entre judíos y cristianos - esto es, una tradición que requiere compartir intereses y proyectos comunes - lo que hay a lo sumo, es una tradición de enemistad y sospecha" ${ }^{29}$. En esta obra, muchas de las intuiciones (ante todo, la distinción entre judío natural y sobrenatural) se retoman de otro modo, ahondando en varios temas, como el anti-cristianismo judío, el problema de la conversión, el silencio del cristianismo frente al Holocausto, la secularización y una cultura predominantemente cristiana y la cierta enemistad entre la teología cristiana y un humanismo judeocristiano.

En 1972 y a modo de divertimento, Cohen imparte una conferencia el 9 de febrero de 1972, de la que solo se editan 1000 copias con un esmero tipográfica y calidad material innegables, sobre Guillaume Apollinaire (1880-1918), el primero inventor del término surrealismo y figura del dadaísmo y el cubismo, el matrimonio formado por Robert Delaunay (1885-1941) y su mujer Sonia, que acuñan el término orfismo para definir una tendencia artística, delicada mezcla de geometría y color y Blaise Cendrars (1887-1961), una de las luces en el firmamento del modernismo contemporáneo. La pasión por el arte y el arte en la escritura no se veían reñidas en absoluto, siendo éste componente estético, una de las características de su obra editorial, la belleza en el contenido y en la forma como modos de ser en el mundo.

En 1973 publica Cohen una serie de conversaciones con su profesor y maestro del Jewish Theological Seminary Mordecai Kaplan. A lo largo de varias entrevistas grabadas en el año $1971^{30}$, conversa, discute y analiza muchos de los temas que debatió en su obra El judío natural y sobrenatural, acerca de su llamado "reconstruccionismo" del judaísmo.

No podía faltar dada su pasión por las vanguardias artísticas de la Unión Soviética, una referencia a Osip Emilievich Mandelstam (1891-1938), poeta acmeísta, deportado a Kolima (una de las probables inspiraciones del Archipielago Gulag de Solshenitzin). Pero esta breve obra de apenas 74 páginas, publicada en 1974, no tendría sentido si no supiéramos que este poeta maldito en su tiempo era también de ascendencia judía. Mandelstam muestra una particular fusión en la que en su persona y obra alternan a veces un judío cristocéntrico, a veces un cristiano judaizante, destacando sin embargo como una figura en la que la enemistad entre judaísmo y cristianismo ocupó un segundo lugar frente a su burla del "montañés del Kremlin" (Stalin, por supuesto) y a esa tragedia, la "conciencia rota que era el hombre soviético",31.

\footnotetext{
${ }^{29}$ Cohen A. (1971), iii.

${ }^{30} 10,14,17,24,25,30$ de septiembre y 1,5 y 7 de octubre de 1971 .

${ }^{31}$ Cohen A. (1974), 74.
} 
En el año 1981 y fruto de cuatro conferencias realizadas entre 1974 y 1979 publica The Tremendum, probablemente una de las obras más relevantes en el siglo XX acerca del Holocausto, la Shoá o la Catástrofe, y que lo insiere dentro de una pléyade de autores que van desde Emil Fackenheim (probablemente el principal) hasta Ignaz Maybaum, Eliezer Berkovits, Elie Wiesel, Primo Levi y Irving Greenberg ${ }^{32}$. Esta obra lo ubica con derecho propio dentro de la llamada "Teología del Holocausto". El término tomado de Rudolf Otto (de nuevo), del capítulo cuatro de su obra Lo Santo, intenta expresar lo que Emil Fackenheim llamaría el "agujero negro de la historia". El suyo es un intento de crear una "gramática del genocidio",33, de expresar en categorías filosóficas, un acontecimiento que bordea lo inefable, convirtiéndose necesariamente en una realidad constitutiva de la identidad del judío frente al gentil ${ }^{34}$.

Cohen realiza una ingente obra editorial. Las obras que llevan su sello específico entran en tres categorías bien diferenciadas: a) antologías y compendios, que pretenden dar cabida a los autores más destacados del momento y sus textos más significativos, b) enciclopedias o diccionarios de conceptos teológicos, filosóficos, sociológicos esenciales para el judaísmo más significativo, redactados por las plumas más ilustres del momento o c) estudios relacionados con artistas y expresiones artísticas que han captado su imaginación como editor. Las introducciones que hace a determinados autores y su perspectiva renacentista del conocimiento lo llevan a cumbres extáticas de la literatura.

Sus compendios y antologías se inician en 1958. En dicho año y con posteriores ediciones en 1960 y 1962, publica un manual de teología cristiana, editado junto con Marvin Halverson. Contiene 103 conceptos teológicos esenciales, centrados, sin embargo y fundamentalmente en el pensamiento protestante $^{35}$, reflejo de otras obras posteriores y del momento histórico y de contexto anglosajón y protestante de los Estados Unidos de América.

La deuda del joven Arthur con quien sería su mentor y figura esencial como representante del judaísmo contemporáneo queda reflejada en La Anatomía de la fe (1960), obra en la que a petición de su viuda Edith Steinberg y sus hijos Jonathan y David, presenta muchos artículos inéditos y otros que no lo son (un total de 7), siendo el editor, el seleccionador y el introductor de quien “ (...) cuyo intelecto y enseñanzas han significado menos que la humanidad y el calor que los conforma" ${ }^{36}$. Los artículos tienen una amplitud extraordinaria de contenido, que van desde la rehabilitación de la palabra "fe", el sentido de la fe religiosa, el anti-intelectualismo de Henri Bergson, reflexiones sobre Reinhold Niebuhr (1892-1971), considerado el más influyente teólogo americano del siglo

\footnotetext{
${ }^{32}$ La inmensidad y diversidad de autores de credos y procedencias diversas es extraordinaria. Para mejor valorar esto, una lectura ineludible (que es un mero punto de partida) es la antología citada:

COHN-SHERBOK, Dan (Editor) (2002).

${ }^{33}$ Cohen A. (1981), 2.

${ }^{34}$ Cohen A. (1981), 22.

${ }^{35}$ Cohen, Arthur A. et al. (Editores). (1962), 5.

${ }^{36}$ Cohen A. (1960), 7.
} 
XX según Arthur Schlesinger Jr., el biógrafo de Kennedy, la visión del judaísmo de Kierkegaard y las novedades de la teología y del pensamiento religioso del siglo XX.

En 1964 dedica un antología de textos a la educación humanística y la civilización occidental, en la que la flor y nata de la intelligentsia norteamericana del momento, reflexionando acerca de la democracia y su futuro, de la importancia del diálogo, de la civilización occidental, de los dilemas de la educación humanística, del papel de las artes en dicha educación y del futuro mismo de las humanidades en una sociedad libre, en la que el "educador" (y aquí se refiere a Robert Maynard Hutchins ${ }^{37}$ ) al afirmar:

“ (...) sea un moralista, el moralista un educador -ya que son intercambiables- es un visionario sin ser apocalíptico, esperanzado sin ser optimista, ansioso sin estar desesperado, irónico sin ser un cínico, abierto sin ser discriminatorio, de principios sin ser un fanático, libre sin ser desordenado" ${ }^{\text {38. }}$.

Su antología de 1970, Argumentos y Doctrinas, se central como indica su subtítulo, en el pensamiento tras el Holocausto. Las preocupaciones de los inicios del siglo XX se ven superadas por la Shoá (el intento de eliminación más sistemático del pueblo judío en la historia) y por el estado de Israel (la posibilidad histórica de la imposibilidad de esa realidad). El tradicional celo religioso se ve sustituido por la necesidad de ahondar en la identidad judía misma, que ha quedado difuminada por la desaparición de aquellas estructuras religiosas que el Antiguo Mundo garantizaba. De modo que el motivo esencial de la antología es "(...) la búsqueda de significados en el judaísmo, en la existencia judía y en el mismo Pueblo Judío"39, siendo “(...) una selección personal y no subjetivo" "40. Son un conjunto de 28 autores, auténticos representantes del judaísmo norteamericano, o autores integrados en el mundo cultural anglosajón norteamericano y canadiense o autores cuya significación no podía pasar desapercibida, como Hannah Arendt, Nahum N. Glatzer, Will Herberg, el propio Cohen, Emil Fackenheim, Ernst Simon, Gershom Scholem, Jacob Taubes y Hans Joachim Schoeps. Se tocan temas como la actualidad de la existencia judía, la renovación de la teología y los retos actuales de las creencias judías.

La otra gran selección que realiza Cohen indica su deuda intelectual al Viejo Mundo. La selección, edición e introducción a la revista Der Jude, revista mensual alemana publicada entre 1916 y 1928 , dirigida y fundada junto con Salman Schocken, por esa luminaria del intelecto que fue Martin Buber. . La selección está hecha en cuatro partes (los judíos y las naciones, la tríada sionismojudaísmo-Alemania, la historia judía y la literatura y pensadores/teólogos). Componen esta selección 22 artículos, entre cuyas plumas ilustres estaban Hermann Cohen, el propio Martin Buber,

37 HUTCHINS, Robert Maynard (1899-1977), educador y pensador estadounidense, ardiente defensor del llamado Perennialismo, una compleja y discutida filosofía fundamentada en un énfasis en la educación superior y la formación de buenos ciudadanos.

${ }^{38}$ Cohen A. (1964), 17.

${ }^{39}$ Cohen, A. (1970), XVII.

${ }^{40}$ Cohen A. (1970), pág. XVIII. 
Leo Strauss, Ernst Simon, Gustav Landauer, Max Wiener, Franz Rosenzweig y Margaret Susman.

En tres ocasiones (1963, 1964, 1973 y de modo póstumo, en 1987), tres obras similares donde la pasión por el libro escrito se manifiesta de forma sublime. En 1963, el Jewish Museum de Nueva York le encarga el catálogo de una exposición tras la apertura del llamado edificio Albert A. List y la reconstrucción del edificio Warburg. La exposición, que tiene un total de 120 piezas de coleccionista y aportaciones de los mejores colectores y museos internacionales, y cuya extensa introducción, pretende ver como la Biblia hebrea (entendida como el conjunto del Pentateuco, los libros proféticos y sapienciales y porciones de los Apócrifos), han influido en la "creación imaginativa de los mundos cristianos, judío y musulmán”. La relación entre arte y teología tiene su sentido cuando Cohen afirma que el arte “(...) el medio por el que puede pensar más claramente, entender de modo más profundo, y amar de forma más ardiente al Dios en el que cree".

En 1973 publica otro catálogo que tiene su origen en la pasión y el coleccionismo del matrimonio Lustig-Cohen de una exposición que duró desde el 17 de septiembre hasta el 21 de octubre de 1973, procedente de la colección de Arthur Cohen y Elaine Lustig, además de la Howard L. and Muriel Weingrow Fine Arts Library of Hofstra University, en la Hofstra University, en Long Island, Nueva York. Un total de 113 ejemplares de Apollinaire, Kandinsky, Walter Gropius, Blaise Cendrars, Le Corbursier, Salvador Dalí, Sonia Delaunay, Marcel Duchamp, Max Ernst, Stéphane Mallarmé y Tristan Tzará entre otros. Póstumamente ya en 1987, en el Jewish Museum de Nueva York le dedica una exposición a las litografías del artista israelí Jakob Steinhardt (1887-1968) del periodo comprendido entre 1907 y 1934.

La Vía negativa de 1964, obra editada privadamente por Cohen, junto con el pintor abstracto, Paul Brach $^{41}$, fue un divertimento, un pequeño libro que contenía doce copias de placas litografiadas por dicho artista. Cohen da rienda suelta a este breve libro (no tendrá más de 12 páginas) con doce litografías que simbolizan a Dios o a el Uno de forma abstracta. Adjunto al mismo, el literato se une al teólogo en un poema de nueve parágrafos ${ }^{42}$. Sendos estudios versarán en 1984 sobre Sonia Delaunay y Herbert Bayer, dando rienda suelta a su pasión artística y que siguen en la misma línea.

Una obra parecida en formato es el estudio que realiza de la comunidad jasídica en 1970, un estudio de esta comunidad tan representativa y carismática del judaísmo, en la que los comentarios escritos y una introducción magnífica, dan rienda suelta al material fotográfico, que resulta de una calidad excepcional.

Finalmente la obra que realiza con Paul Mendes-Flohr en 1987 es uno de los mayores testimonios al tesón y el trabajo de su última época y especialmente de sus últimos meses de vida, donde incluso sus preocupaciones familiares y personales ocuparon segundo plano frente a la obra que debía completar. A lo largo de más de 1100 páginas y en los últimos ocho meses de su vida, llevó a cabo una tarea ingente para reflejar en 120 términos, lo fundamental del pensamiento religioso judío del siglo XX (conceptos como autoridad, Pueblo Escogido, mandamientos, eternidad y tiempo,

\footnotetext{
${ }^{41}$ BRACH, Paul (1924-2007), pintor abstracto, conferenciante y educador norteamericano.

${ }^{42}$ Stern, D. \& Mendes-Flohr, P. (1998), p. 55
} 
existencia, gnosis, hermenéutica, teoría política, Talmud, teodicea, etc) a través de una pléyade de los autores más significativos de finales del siglo XX, como son David Stern, David Flusser, Paul Mendes-Flohr, el propio Cohen, Geoffrey Wygoder (el redactor en jefe de la primera edición de la Encyclopedia Judaica), Shalom Rosenberg, David Biale, Emil Fackenheim, Moshe Idel y Hyam Maccoby, entre tantos otros.

La ficción narrativa es para Cohen, un elemento más de su reflexión teológica. Probablemente el mejor estudio de los mismos lo ha hecho Emily Kopley ${ }^{43}$, junto con Claire R. Satlof ${ }^{44}$. Cinco son las novelas como d que engloban su faceta más artísticas, que no es más que una teología literaria, o como diría la propia Satlof, la novela (especialmente la primera), es “(...) una introducción a como su ideología conforma su ficción" 45 , relata el caso de Edgar Morrison, un judío converso, director de un centro de clara orientación cristiana, que se ve afectado por la repentina presencia de su hijo, que se entrevista en la Pensilvania rural, para propiciar un acercamiento a su padre. Ambos representarían posturas distantes, un padre que la negación de su dimensión sobrenatural y un hijo, que asume en su identidad, tanto al judío natural como al sobrenatural. En su siguiente obra In the Days of Simon Stern (1973), Simon Stern, un autoproclamado Mesías en Nueva York se rodea de supervivientes del Holocausto para reconstruir el templo en el Lower East Side, en la que se entremezclan los grandes mitos del exilio y la redención. En A Hero in His Time (1976), a un oscuro poeta judío ruso se le pide que de una conferencia en Nueva York, una figura "natural" como editor y "sobrenatural" como poeta ${ }^{46}$ y una figura con un notable perfil autobiográfico. En Acts of Theft (1980), un ladrón de arte pre-colombino considera que la obra de arte tiene una dimensión divina, que finalmente crea sus propios ídolos, para como Cohen “(...) atrapar el sentido de un pasado humano colectivo y la especificidad de su propio mundo" 47 . En An Admirable Woman (1983), se nos describe la vida de un personaje femenino, que muchos creen basado en la figura de Hannah Arendt, Erika Hertz nacida en Berlín pero afincada en Nueva York, profesora e intelectual, una figura que tiene problemas para conciliarse con su identidad judía, una especie de autobiografía o de memorias, de final incierto. La última obra Artists and Enemies. Three Novellas de 1987, un conjunto de tres novelas publicadas de forma póstuma, convirtiéndolo en "un escritor de escritores y el tesoro de un lector".

La vida de Cohen es por tanto rica, de una intensidad intelectual increíble pero el momento clave, primero personal y luego redactado, es el momento en el que se manifiesta con absoluta contundencia, la decisión, la "elección" de lo que habría de ser, el método, la regla de su vida entera.

\footnotetext{
${ }^{43}$ Morgan, M. \& Weitzman, S. (2015), 372-403.

${ }^{44}$ Shatzky, J. \& Taub, M. (1997), 47-50.

${ }^{45}$ Shatzky, J. \& Taub, M. (1997), 47.

${ }^{46}$ Morgan, M. \& Weitzman, S. (2015), 392-393.

${ }^{47}$ Shatzky, J. \& Taub, M. (1997), 49.
} 


\section{Por qué escojo ser judío $(1959)^{48}$}

Cohen, en 1959, describe su viraje hacia el judaísmo, su camino hacia la "herencia religiosa" de sus padres, que como muchos de sus congéneres, habían abandonado o desistido de practicar. El determinismo de "pertenecer" a la comunidad judía ya no existe. En la América en la que vive, no fue la primera generación (la emigración del Viejo Mundo, de Europa) la que cambió el status quo de sus hijos, ni la segunda que aseguró la estabilidad económica de sus familias así como la lucha en contra del antisemitismo, sino que es esa "tercera generación" a la que él pertenece, la que es libre de ser judía, no está obligado a serlo y en todo caso, como mucho se ve en la disyuntiva de repudiar al judaísmo o abrazar al cristianismo ${ }^{49}$. Cohen elige libremente ser judío:

"Dada la libertad de escoger he decidido abrazar el judaísmo. No lo he hecho por lealtad al Pueblo Judío ni al Estado Judío. Mi elección ha sido religiosa. Escojo creer en el Dios de Abraham, de Isaac y de Jacob, reconocer la ley de Moisés como la Palabra de Dios, aceptar al pueblo de Israel como el instrumento sagrado del cumplimiento de la voluntad divina y esperar la venida del Mesías y la redención de la historia" $" 50$.

Esta es la solemne afirmación de Cohen cuando tiene 31 años, aunque fuera un texto, resultado de una meditación de años. Sin desmerecer el esfuerzo de sus padres por procurarle sustento, su escasa observancia religiosa, la fuerza de una cultura cristiana predominante en todos los ámbitos de la vida (especialmente la académica), fue gracias a Milton Steinberg, que en un camino que partía del cristianismo para volver a las fuentes de su herencia cultural, llega a la inevitable conclusión que “(...) el judaísmo no era un destino inevitable, sino un destino que podía escogerse libremente" ${ }^{\text {" }}$. El camino que siguió para ello fueron el estudio, la reflexión, el pensamiento, en definitiva, la teología, a la que reivindica vehementemente ${ }^{52}$. Esta desconfianza de la teología por parte del judaísmo (no presente en el cristianismo con su disciplina, exigencias, leyes y dogmas) es reflejo de centrarse del judaísmo en el "acto", en la acción, en la acción justa y no la especulación ni la fe.

Cohen precisamente plantea la desconfianza del judaísmo frente a la teología como una reacción al cristianismo, que ese "pasatiempo" de los gentiles pueda llegar algún dia a "cristianizar" al judaísmo; frente a la fe, al dogma y la teología, el judaísmo enfatiza la observancia de la Ley de Dios y no la especulación acerca de ella. Cohen mismo se define como "converso" al judaísmo,

\footnotetext{
${ }^{48}$ Stern, D. \& Mendes-Flohr, P. (1998), 32-41.

${ }^{49}$ Stern, D. \& Mendes-Flohr, P. (1998), 33.

${ }^{50}$ Stern, D. \& Mendes-Flohr, P. (1998), 33.

${ }^{51}$ Stern, D. \& Mendes-Flohr, P. (1998), 35.

${ }^{52}$ Stern, D. \& Mendes-Flohr, P. (1998), 35.
} 
pero un converso que cree en la primacía de la teología ${ }^{53}$. El pensamiento complementa a la creencia. Aun así, ser creyente no supone dejar, abandonar o incluso librarse de la duda y la desesperación. Cohen no niega que su postura o su antecedentes sean originales y evidentemente comparten lo esencial del credo judín ${ }^{54}$. Por eso mismo, Cohen afirma con total rotundidad los cuatro puntos de su punto de vista:

a) Escojo creer en el Dios de Abraham, Isaac y Jacob;

b) La Ley de Moisés es la Palabra de Dios;

c) Que el Pueblo Judío ha sido elegido como instrumento especial de Dios y,

d) Que Jesús no es el Mesías del que habla la Bíblia, que el cristianismo ha concebido una imagen imperfecta del final y que un Mesías, que todavía ha de venir, será quien redimirá la historia ${ }^{55}$.

Aunque el camino adoptado por Cohen es el de la reflexión teológico-racional, él mismo reconoce los límites de lo intelectual, para afirmar con rotundidad, que “(...) para mí, creer en el Dios bíblico, el Dios de los Patriarcas, la montaña humeante, la zarza ardiente, no es someter a la razón, sino ir más allá de ella" ${ }^{, 56}$. Es creer en un Dios que actúa en la historia y se dirige al hombre para ello y que implicándose en la Creación, le prepara para la redención.

El primer punto refleja que la grandeza y la miseria de la existencia diaria del hombre sólo se entienden si consideramos a la Biblia, a la Revelación de Dios como una afirmación sólo aceptable “(...) sólo si creo en un Dios al que me pueda dirigir como Señor, Señor"57.

El segundo punto reconoce que la santidad (objeto primordial de la religión) sólo se consigue mediante la revelación de la Torá y a través de la Voluntad Divina, expresada en la observación de los mandamientos divinos, siendo no obstante y de modo esencial, “(...) auténticamente conscientes de la sagrada intención de estos" ${ }^{, 58}$, frente al mero ritualismo.

El tercer punto alude al proceso de elección del Pueblo Judío como el Pueblo de Dios, siendo como debe ser justo ejemplo entre todas las naciones pero consciente a su vez, de sus errores, debilidades e iniquidades. La "santidad de la comunidad" tiene en su supervivencia, la muestra más contundente del sentido de su sufrimiento, que hace de su elección y de su misión, algo necesario en el mundo ${ }^{59}$.

El cuarto punto implica a todas las naciones, el mundo entero. Este, en su totalidad, debe preparar el camino del Mesías y crear las condiciones de posibilidad de su misión salvífica. Y este es el punto

\footnotetext{
${ }^{53}$ Stern, D. \& Mendes-Flohr, P. (1998), 36.

${ }^{54}$ Stern, D. \& Mendes-Flohr, P. (1998), 41.

${ }_{56}^{55}$ Stern, D. \& Mendes-Flohr, P. (1998), 36, 37, 39 y 40 resspectivamente.

${ }^{56}$ Stern, D. \& Mendes-Flohr, P. (1998), 36.

${ }^{57}$ Stern, D. \& Mendes-Flohr, P. (1998), 37.

${ }^{58}$ Stern, D. \& Mendes-Flohr, P. (1998), 38.

${ }^{59}$ Stern, D. \& Mendes-Flohr, P. (1998), 39.
} 
de contención con el Cristianismo, no que un solo precursor (Juan Bautista) preparara el camino para Jesús y que este fuera el Ungido, sino que al modo de la arenga de Marx, el Pueblo Judío no ha venido al mundo a interpretarlo, cuanto a cambiarlo.

\section{El judío natural y sobrenatural (1962)}

Emily Kopley afirma que ésta es sin lugar a dudas, la obra que convierte al joven escritor en un teólogo de primera ${ }^{60}$. La obra, dividida en cuatro capítulos y a lo largo de más de 300 páginas abarca en su capítulo primero, el llamado "siglo de la incerteza" (donde aborda los autores judíos más relevantes desde el siglo XV hasta el primer tercio del siglo XX: Solomon Ibn Verga, Moses Mendelssohn, Nahman Krochmal, Leopold Zunz, Heinrich Graetz, Samson Raphael Hirsch, Moses Hess, Ahad Ha-Am, Simon Dubnow y Chaim Nachman Bialik).

La segunda parte la dedica al llamado "Renacimiento judeogermano" (hablando de Hermann Cohen, Leo Baeck, Franz Rosenzweig y Martin Buber). En la tercera, habla ya por primera vez, del llamado "momento americano" del judaísmo (Mordecai Kaplan, Milton Steinberg, Abraham Joshua Heschel y Will Herberg), para finalmente en la cuarta, hablar de la "vocación de la mente judía", donde da rienda suelta a una "metafísica de la historia" y a la "teología como la ciencia de la historia sagrada", cuyo contenido quedará reflejado en las conclusiones.

La dimensión natural y sobrenatural del judío le viene de su realidad específica: la horizontalidad, en tanto que pueblo inmerso en la historia y parte de de las "demás naciones" y en su verticalidad, en su relación con la transcendencia, como el "pueblo elegido" del Dios de Abraham, Isaac y Jacob. Pero ¿qué significa de facto, esta distinción?

Cohen establece cinco dogmas esenciales, cinco conceptos sin los que no se entiende su obra teológica, dogmas que no deben entenderse en el sentido estricto de la palabra, cuanto aquellos puntos de partida que le van a permitir expresar su "propia" visión de lo que supone ser judío. Tienen un triple carácter: empírico (la realidad cotidiana del judío), histórico (al expresar el significado y enseñanzas del judío entre las naciones) y transhistórico (la dimensión metafísica, teológica y su consciencia de un destino) ${ }^{61}$. Todo ello conforma su autocomprensión de lo que supone ser judío en este momento histórico ${ }^{62}$. Estos no son meramente una declaración de principios, o en sus propias palabras: "Las afirmaciones que me preceden (...) definen algo infinitamente más precioso que el triunfo del pensamiento y los argumentos. Son lo que me permiten entenderme a mí mismo como judío"63. Su planteamiento del significado del judaísmo tiene un carácter esencialmente histórico, pero no sólo plantea si un hecho ha sucedido, sino lo que

\footnotetext{
${ }^{60}$ Morgan, M. \& Weitzman, S. (2015), 375.

${ }^{61}$ Cohen A. (1962), 5.

${ }^{62}$ Cohen A. (1962), 5.

${ }^{63}$ Cohen A. (1962), 7.
} 
es más importante "por qué" sucedió. El sentido mismo de la historia se torna una realidad existencial, cada momento "(...) el prisma en el que la turbia luz de la historia y la clara luz de Dios se convierten en una sola cosa" ${ }^{\prime \prime}$.

Los principios esenciales, el punto de partida metodológico que define la relación entre el judío natural y el sobrenatural, y de facto, la teología de Cohen se basa en cinco "dogmas" y no deja de ser irónico su empleo de un término asociado al cristianismo.

Los dogmas son cinco:

a) La distinción entre el judío natural y el sobrenatural. El judío natural es esencialmente un ser incardinado en la naturaleza y en la historia. Todo cuanto le rodea le limita, su lugar de nacimiento, su lengua, la cultura y trabajo que realiza. Sólo al abrirse a la transcendencia, pasa del determinismo, de la limitación a conocer su destino. La vocación sobrenatural del judío, que sólo se produce mediante la Alianza que establece con su Dios, le posibilita transcender sus límites naturales e históricos. El verdadero significado de la vida del judío le viene de su vocación sobrenatural, en el sentido que es Dios mismo quién le ha llamado para estar con Él ${ }^{65}$.

b) Tener una vocación sobrenatural es esencial. Para ello resulta imprescindible el concepto de Exilio, que no se pierde por la falsa seguridad de una Diáspora o un Estado de Israel, sino que se convierte en "concepto teológico" entendido como un "no-serredimido" $"$.

c) Esta irredención supone la incompletitud esencial de toda historia, convirtiendo al judío en un ser mesiánico para el que no hay redención hasta la que misma historia se "redima"; 67

d) Es el Pueblo de Dios el elegido para la Alianza y este sentido para su propia redención, que sin embargo, no le pertenece exclusivamente, sino que debe ser compartir con los demás pueblos ${ }^{68} \mathrm{y}$,

e) La dimensión natural y sobrenatural del judío supone que ambas se complementan y dependen necesariamente la una de la otra, y dicha dimensión está tan sujeta al devenir histórico como a la invariabilidad de los mandatos divinos ${ }^{69}$.

El judío vive entre dos momentos, el de la "creación” y el de la "redención”. Estas son afirmaciones fundamentalmente "existenciales", porque su poder y verdad se fundamentan en una decisión que se toma en relación a dos parámetros, el de la historia y el de una "tarea eterna"70.

\footnotetext{
${ }^{64}$ Cohen A. (1962), 8.

${ }^{65}$ Cohen A. (1962), 6.

${ }^{66}$ Cohen A. (1962), 6.

${ }^{67}$ Cohen A. (1962), 6-7.

${ }^{68}$ Cohen A. (1962), 7.

${ }^{69}$ Cohen A. (1962), 7.
} 


\section{Teología e identidad judía}

Cohen es un autor singular. Es un erudito, es un maestro de la palabra escrita y de la belleza intrínseca del libro. Su teología es un intento esencial de entenderse a sí mismo como un "judío" que se ha erigido como una isla en medio de un mar de cristianismo militante y adverso. Para ello debe entenderse a sí mismo y lo hace mediante una declaración de principios o de dogmas (palabra poco adecuada y que tiene connotaciones poco judías, pero que emplea) y un texto donde se "afirma" como judío y que articulan la esencia teológica, filosófica e histórica del significado del judaísmo y del judío en el mundo contemporáneo.

La perspectiva de la que parte es la de la asimilación, a la que sin embargo, se resiste. El suyo es un intento de reivindicación de la esencia misma del judaísmo, en una modernidad o época contemporánea (que en el contexto norteamericano) ignora el fundamento religioso del judaísmo. Quizás sus principios no sean del todo originales, aunque sí su afirmación fundamental: que siendo un judío asimilado, de tercera generación, que bien podía haberse convertido al cristianismo, decide abiertamente y libremente, "ser judío", reivindicar su judaísmo y la pertenencia al Pueblo Elegido. Su camino: la teología. Su punto de partida: el cristianismo. Su necesidad: entenderse a sí mismo y reclamar su herencia, la que le fue negada y la que le corresponde, aunque sólo sea por vía del parentesco (que no lo es).

Su vida es obra y muestra de esta declaración de principios. Se divide entre su propio sentido de autoafirmación y la comprensión del pensamiento judío contemporáneo (y no exclusivamente norteamericano) que tiene como horizonte, el Holocausto, el Tercer Jurbán o Destrucción del Templo (Ignaz Maybaum) o el agujero negro de la historia (Emil Fackenheim).

Su concepto de identidad judía parte de un discurso teológico, racional que supera con creces, la dimensión del acto justo, pero que a la vez, lo complementa. Cohen se basa en los conceptos esenciales del judaísmo, defendiendo una perspectiva que articula una nueva visión para el hombre moderno y que pretende dar un nuevo sentido al judaísmo para el hombre de hoy, planteando una "filosofía de la historia", que da primacía a la cosmovisión judaica pero que no ignora ni el pasado histórico ni el "momento americano" del pensamiento desarrollado en Norteamérica. La suya es una visión compleja, innovadora pero que conserva sus raíces. No sale del tradicionalismo pero lo intenta. Su intento de comprensión de su propia fe es lo que vertebra los inicios de su reflexión teológica, pero sólo será más tarde, cuando inicie sus pensamientos acerca de la relación entre judaísmo y cristianismo, pero especialmente su interpretación del Holocausto a través del Tremendum, que mostrará su fuerza argumentativa. Cohen es un autor complejo, poco analizado y difícil de entender, aunque el intento vale la pena por su singularidad, su empeño y su poco transitado estudio.

\footnotetext{
${ }^{70}$ Cohen A. (1962), 7.
} 


\section{BIBLIOGRAFÍA}

\section{Obras de Arthur Allen Cohen}

\section{Ensayo filosófico-teológico}

COHEN, Arthur A. Martin Buber (1957). London, Bowes \& Bowes.

COHEN, Arthur A. The Natural and the Supernatural Jew. An Historical and Theological Introduction (1962). New York, Pantheon Books. (Cf. London, Vallentine-Mitchell, 1967).

COHEN, Arthur A. The Communism of Mao Tse-tung (1964). Chicago, University of Chicago Press (Phoenix Edition, 1966).

COHEN, Arthur A. The myth of the Judeo-Christian Tradition and other Dissenting Essays (1971). New York, Schocken Books.

COHEN, Arthur A. The Delaunays, Apollinaire and Cendrars. (1972). New York, The Cooper Union School of Art and Architecture.

COHEN, Arthur A. If not now, when? Toward a Reconstitution of the Jewish People. Conversations between Mordecai M. Kaplan and Arthur A. Cohen (1973). New York, Schocken Books.

COHEN, Arthur A. Osip Emilievich Mandelstam. An Essay in Antiphon (1974). Michigan, Ardis.

COHEN, Arthur A. The Tremendum. A Theological Interpretation of the Holocaust (1981). New York, Crossroad.

\section{Editor (antologías y catálogos)}

COHEN, Arthur A. (Edición e introducción). The Anatomy of Faith: Theological Essays of Milton Steinberg (1960). California, Harcourt Brace.

COHEN, Arthur A. y HALVERSON, Marvin (Editores). (1962). A Handbook of Christian Theology. Essential Information for every Christian. Great Britain, Collins (Fontana Books).

COHEN, Arthur Allen. The Hebrew Bible in Christian, Jewish and Muslim Art. (1963) New York, The Jewish Museum.

VV.AA. COHEN, Arthur A. (Edición e introducción) (Mortimer J. Adler, Elisabeth Mann Borgese, Scott Buchanan, William O. Douglas, Philip C. Jessup, Bertrand de Jouvenel, Humayun Kabir, Milton Mayer, Richard P. McKeon, John Courtney Murray S.J., David Riesman, Rexford G. Tugwell, F. Champion Ward y O. Meredith Wilson,). Humanistic education and Western civilization (1964). New York, Reinhart and Winston.

COHEN, Arthur A. (Editor) (Fotografías realizadas por Philip Garvin). People Apart. Hasidism in America. Photographs by Philip Garvin. Text by Arthur A. Cohen (1970). New York, E.P. Dutton \& Co. Inc. 
COHEN, Arthur A. Arguments and Doctrines. A Reader of Jewish Thinking in the Aftermath of the Holocaust. Selected with Introductory Essays by Arthur A. Cohen (1970). New York, Evanston and London, Harper \& Row Publishers.

COHEN, Arthur A. The Book Stripped Bare. A Survey of Books by 20th Century Artists and Writers (1973). Long Island/Nueva York.

COHEN, Arthur A. (Selección, edición e introducción por Cohen). The Jew. Essays from Martin Buber's Journal Der Jude, 1916-1928. Translated from the German by Joachim Neugroschel (1980). Alabama, The University of Alabama Press.

COHEN, Arthur A. Sonia Delaunay. Text by Arthur A. Cohen. (1984). New York, Harry N. Abrams Inc.

COHEN, Arthur A. Herbert Bayer. The Complete Work. (1984). CambridgeMassachusetts/London-England, The MIT Press.

COHEN, Arthur A. The Unknown Steinhardt. Prints by Jakob Steinhardt produced between 1907 and 1934. (1987) New York, The Jewish Museum (Obra póstuma).

COHEN, Arthur A. \& Mendes-Flohr, Paul (Editores) (1987) Contemporary Jewish Religious Thought. Original Essays on Critical Concepts, Movements and Beliefs. New York, The Free Press.

\section{Obra novelística}

COHEN, Arthur A. The Carpenter Years (1967). New York, The New American Library.

COHEN, Arthur A. In the Days of Simon Stern (1973). New York, Random House.

COHEN, Arthur A. A Hero in His Time (1976). Chicago and London, The University of Chicago Press.

COHEN, Arthur A. Acts of Theft (1980). Chicago and London, The University of Chicago Press.

COHEN, Arthur A. An Admirable Woman (1983). Boston, David R. Gordine Publisher.

COHEN, Arthur A. Artists and Enemies. Three Novellas (1987). Massachussets, David R. Gordine Publisher.

\section{Antología}

STERN, David \& MENDES-FLOHR, Paul. An Arthur A. Cohen Reader. Selected Fiction and Writings on Judaism, Theology, Literature and Culture. Detroit, Wayne State University Press, 1998.

\section{Bibliografía sobre Arthur Allen Cohen}


COHN-SHERBOK, Dan. (1996). Fifty Key Jewish Thinkers (1997). London, Routledge (“Arthur Allen Cohen (1928-1986), pág. 27-30).

CRONIN, Gloria L. \& BERGER, Alan (Editores) (2009). Encyclopaedia of Jewish-American Literature. New York, Facts on File Inc., ("Cohen, Arthur Allen (1928-1986)", pág. 52-53. (Alan L. Berger).

GIMÉNEZ BLUNDEN, Miguel (2012). Arthur Allen Cohen y el Tremendum. Una aproximación teológica a la Shoah. Revista El Olivo, 75, 87-106.

GIMÉNEZ BLUNDEN, Miguel. (2015). Arthur Allen Cohen: ser judío en América. Cuadernos Judaicos, 32 (Diciembre), 107-128. DOI: 10.5354/0718-8749.2015.38068.

LEVINSON, J. Arthur A. Cohen's Resplendent Vision (2003). Prooftexts, 23 (1), 259-267. DOI: $10.1353 /$ ptx.2003.0022

KATZ, Steven T.

- Post-Holocaust Dialogues. Critical Studies in Jewish Modern Thought. New York \& London, New York University Press, 1983.

- Historicism, The Holocaust and Zionism. Critical Studies in Modern Jewish Thought and History. New York \& London, New York University Press, 1992 (10. "The Tremendum": Arthur Cohen's Understanding of Faith after the Holocaust, p. 251-273).

KOPLEY, E. Arthur A. Cohen's Debt to Elie Wiesel (2009). Studies in American Jewish Literature, 28, 28-40. URL: https://www.jstor.org/stable/41206112.

KOPLEY, E. 20th Century Jewish Religious Thought: Original Essays in Critical Concepts, Movements, and Beliefs ed. by Arthur A. Cohen, Paul Mendes-Flohr (Recensión). Studies in American Jewish Literature, Vol. 32, (1), enero 2013, 99-102.

MORGAN, Michael L. Beyond Auschwitz. Post-Holocaust Jewish Thought in America (2001). Oxford University Press (“Arthur Cohen and the Holocaust as Tremendum”, pág. 141-154).

MORGAN, M. \& WEITZMAN, S. Rethinking the Messianic Idea in Judaism. Bloomington and Indianapolis, Indiana University Press, 2015. (Emily Kopley, "Arthur A. Cohen's Messianic Fiction", pág. 372-403).

SHATZKY, Joel \& TAUB, Michael (Editores). Jewish-American Novelists. A Bio-Critical Sourcebook (1997). London/Westport-Connecticut, Greenwood Press, (Claire R. Satlof, "Arthur Allen Cohen (1928-1986)", pág. 46-54. 


\section{Bibliografía secundaria esencial}

BERKOVITZ, Eliezer. Faith after the Holocaust. New York, Ktav Publishing House Inc., 1973.

COHN-SHERBOK, Dan (Editor). Holocaust Theology. A Reader. New York, New York University Press, 2002.

De LANGE, Nicholas (Editor). Ignaz Maybaum. A Reader. New York/Oxford, Berghahn Books, 2001.

FACKENHEIM, Emil. An Epitaph for German Judaism: From Halle to Jerusalem (2007). Madison (Wisconsin, EE.UU.), The University of Wisconsin Press.

MAYBAUM, Ignaz. The Face of God After Auschwitz. Ámsterdam, Polak \& Van Gennep Ltd., 1965.

NOVICK, Peter. The Holocaust in American Life. (1999). New York, Houghton Mifflin Company.

RUBENSTEIN, Richard L.

- After Auschwitz. History, Theology and Contemporary Judaism (1992). Baltimore (EE.UU.), The Johns Hopkins University Press.

- The Cunning of History. The Holocaust and the American Future (1987). New York, Harper Perennial, 2001. 